\title{
Redo transapical aortic valve implantation: Feasibility of a repeat approach through the left ventricular apex
}

\author{
Darrin M. Payne, MD, Josep Rodés-Cabau, MD, FESC, Daniel Doyle, MD, and \\ Eric Dumont, MD, Quebec, Canada
}

Transapical aortic valve implantation (TA-AVI) is a treatment option for severe aortic stenosis (AS). Perivalvar leaks are common. ${ }^{1,2}$ They can often be resolved with repeat balloon expansion, but implanting a second valve may be required. We present a patient who developed a perivalvar leak 2 days after TA-AVI and underwent a second operation through the original apical access site.

\section{CASE REPORT}

A 78-year-old man presented with angina and dyspnea. Comorbidities included peripheral vascular disease, obstructive lung disease, and renal insufficiency. He had undergone two sternotomies for bypass surgeries. Cardiac catheterization revealed patent grafts to the left anterior descending and obtuse marginals. He had occluded grafts to his right coronary artery that had a 70\% proximal stenosis. Echocardiogram (ECHO) showed an ejection fraction of $30 \%$ and severe AS. Because of unsuitable access vessels he was offered TA-AVI.

The left ventricular (LV) apex was exposed as described previously. ${ }^{3}$ A 26-mm Edwards SAPIEN valve (Edwards Lifesciences Inc, Irvine, Calif) was positioned and deployed. Transesophageal ECHO (TEE) revealed a trivial perivalvar leak. The following day, the patient experienced flash pulmonary edema requiring reintubation. Angiography revealed unchanged coronary anatomy, a well-seated valve, but a new moderately-severe perivalvar leak. This was confirmed with ECHO (Figure 1). The symptoms persisted. On postoperative day 5 the decision was made to address the perivalvar leak.

Via the right axillary artery a 25-mm NuMed Balloon (NuMED Canada Inc, Cornwall, Ontario, Canada) was introduced and valvuloplasty performed. The leak persisted and the decision was made to reimplant a second valve as described previously. ${ }^{4}$ The LV apex was re-exposed via the same incision. Clot and inflammatory phlegmon en-

\footnotetext{
From the Institut Universitaire de Cardiologie et de Pneumologie de Québec, Quebec, Canada.

Disclosures: Authors have nothing to disclose with regard to commercial support.

Received for publication July 8, 2010; revisions received Aug 3, 2010; accepted for publication Aug 10, 2010; available ahead of print Oct 6, 2010.

Address for reprints: Eric Dumont, MD, Institut Universitaire de Cardiologie et de Pneumologie de Québec, 2725 Chemin Ste-Foy, Quebec, G1V 4G5, Canada

(E-mail: Eric.Dumont@criucpq.ulaval.ca).

J Thorac Cardiovasc Surg 2011;141:1077-8

$0022-5223 / \$ 36.00$

Copyright (c) 2011 by The American Association for Thoracic Surgery

doi:10.1016/j.jtcvs.2010.08.009
}

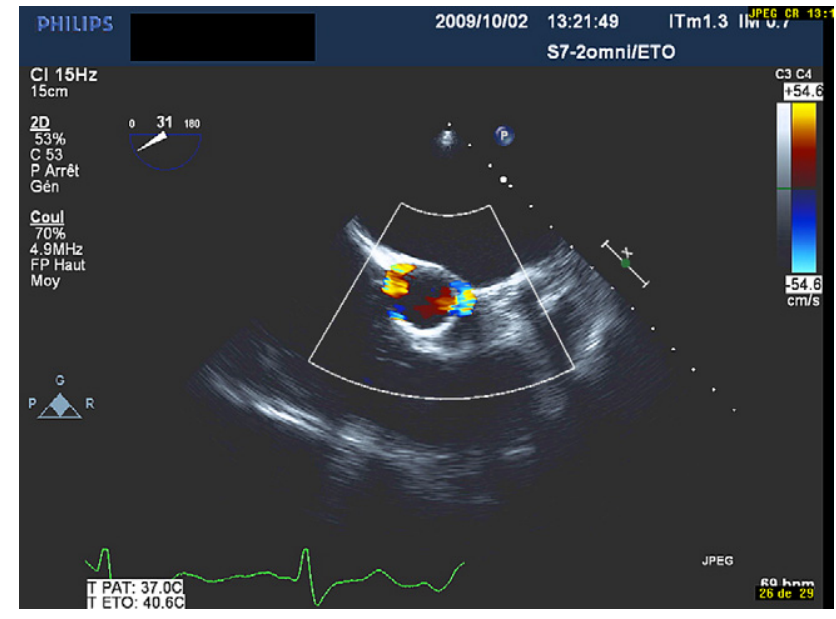

FIGURE 1. Perivalvar leak.

cased the previous closure, but adhesions were minimal and exposure readily achieved. Two 2-0 Ethibond pledgeted U-stitches were widely placed encompassing the previous ventriculotomy site. Tissue integrity was comparable to the initial operation. Without reopening our previous ventriculotomy, our wires and introducers were passed similar to a primary procedure. A second 26-mm Edwards SAPIEN valve was deployed within the first, achieving good position and stable seating (Figure 2). A mild perivalvar leak was evident on TEE and was deemed acceptable. The LV apex was closed routinely using the U-stitches. The patient did well and suffered no adverse complications.

\section{COMMENT}

Although unclear why the leak progressed, it is possible the valve migrated very slightly, or a small fragment of calcium dislodged opening a passage for flow. In this case, we selected the right axillary artery as our access vessel to avoid the diseased ileo-femoral vessels. Although ballooning the valve via this approach was practical, the curvature and angulation of the axillary artery made a transcatheter approach impossible. Because we were uncertain how the LV apex would respond to a second puncture, the axillary artery afforded rapid access for cardiopulmonary bypass (CPB) should it be required. Wide placement of our U-stitches encompassing the previous ventriculotomy site permitted a solid hemostatic closure.

To our knowledge, this is the first report of redo TA-AVI in the perioperative period, thus demonstrating its 


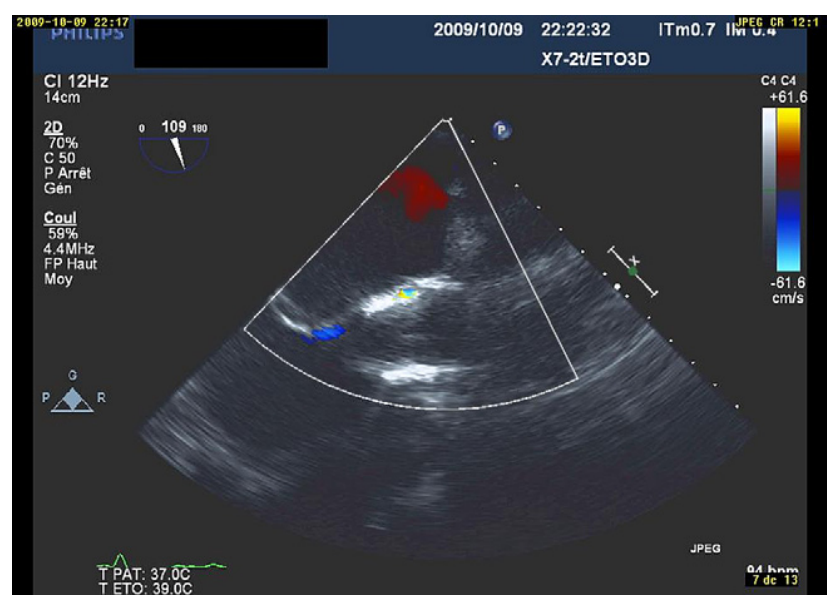

FIGURE 2. Valve-in-valve placement.

feasibility. A major concern is retraumatizing the LV apex, with consequent tearing and hemorrhage. Although we at- tained adequate hemostasis using conventional techniques, we would urge others to select and expose access vessels for CPB should it be urgently required during the procedure.

\section{References}

1. Vahanian A, Alfieri OR, Al-Attar N, Antunes MJ, Bax J, Cormier B, et al. Transcatheter valve implantation for patients with aortic stenosis: a position statement from the European Association of Cardio-Thoracic Surgery (EACTS) and the European Society of Cardiology (ESC), in collaboration with the European Association of Percutaneous Cardiovascular Interventions (EAPCI). Eur J Cardiothorac Surg. 2008;34:1-8.

2. Rodés-Cabau J, Webb JG, Cheung A, Ye J, Dumont E, Feindel CM, et al. Transcatheter aortic valve implantation for the treatment of severe symptomatic aortic stenosis in patients at very high or prohibitive surgical risk. Acute and late outcomes of the multicenter Canadian experience. J Am Coll Cardiol. 2010;55: 1080-90.

3. Walther T, Dewey T, Borger MA, Kempfert J, Linke A, Becht R, et al. Transapical aortic valve implantation: step by step. Ann Thorac Surg. 2009;87:276-83.

4. Rodés-Cabau J, Dumont E, Doyle D. "Valve-in-valve" for the treatment of paravalvular leaks following transcatheter aortic valve implantation. Catheter Cardiovasc Interv. 2009;74:1116-9.

\title{
A combined procedure of thoracoabdominal aortic aneurysm repair and coronary artery bypass grafting: Report of two cases
}

\author{
Saina Attaran, MRCS, Mark Field, FRCS, Manoj Kuduvalli, FRCS, and Aung Oo, FRCS, Liverpool, \\ United Kingdom
}

The prevalence of coronary artery disease in patients with aneurysm of the aorta is $40 \%$ to $60 \%{ }^{1,2}$ Coronary artery disease is a significant predictor of early mortality after aneurysm repair. ${ }^{3,4}$ Therefore, coronary artery revascularization before the repair of aneurysms is recommended but carries a $10 \%$ risk of perioperative aneurysm rupture. ${ }^{5}$ Moreover, a 2 -staged approach will leave the patient with 2 scars, twice the hospitalizations, and an increase in interval delays.

We describe a successful combined procedure of thoracoabdominal aortic aneurysm (TAAA) repair and coronary artery bypass grafting (CABG) performed in 2 cases.

\footnotetext{
From the Thoracic Aortic Aneurysm Service, Liverpool Heart and Chest Hospital, Liverpool, United Kingdom.

Disclosures: Authors have nothing to disclose with regard to commercial support.

Received for publication Feb 8, 2010; revisions received June 23, 2010; accepted for publication July 12, 2010; available ahead of print Aug 30, 2010.

Address for reprints: Saina Attaran, MRCS, Liverpool Heart and Chest Hospital NHS Foundation Trust, Thomas Dr, Liverpool, L14 3PE, United Kingdom (E-mail: saina.attaran@kcl.ac.uk)

J Thorac Cardiovasc Surg 2011;141:1078-9

0022-5223/\$36.00

Copyright (C) 2011 by The American Association for Thoracic Surgery

doi:10.1016/j.jtcvs.2010.07.022
}

\section{CLINICAL SUMMARY \\ Patient 1}

A 64-year-old man who presented with back pain underwent a computed tomographic (CT) scan that confirmed a contained rupture of a Crawford extent II TAAA $(6.5 \mathrm{~cm})$. He also had a significant history of angina. Coronary angiogram showed a severe segment of stenoses in the circumflex artery and an unstable plaque in the dominant right coronary artery. The possibility of percutaneous intervention was discussed with the cardiologists; the coronary anatomy was considered not suitable for this treatment.

\section{Patient 2}

A 64-year-old man with history of myocardial infarction and recent angina was known to have a Crawford extent II TAAA aneurysm $(11.5 \mathrm{~cm})$. The angiogram demonstrated an occluded left anterior descending artery, but stress magnetic resonance imaging revealed inducible ischemia in its territory.

The sequence of treatment is controversial; we planned to perform a single-stage procedure to repair the aneurysm and revascularize the heart simultaneously. 